Bull. Mater. Sci., Vol. 35, No. 6, November 2012, pp. 939-946. (c) Indian Academy of Sciences.

\title{
Comparison of galvanic displacement and electroless methods for deposition of gold nanoparticles on synthetic calcite
}

\author{
CHAMARTHI K SRIKANTH and P JEEVANANDAM* \\ Department of Chemistry, Indian Institute of Technology Roorkee, Roorkee 247 667, India
}

MS received 20 September 2011; revised 13 October 2011

\begin{abstract}
Gold nanoparticles have been deposited on synthetic calcite substrate by galvanic displacement reaction and electroless deposition methods. A comparative study has shown that electroless deposition is superior compared to galvanic displacement reaction for uniform deposition of gold nanoparticles on calcite. Characterization of the samples, prepared by two different deposition methods, was carried out by X-ray diffraction, transmission electron microscopy, field emission scanning electron microscopy (FE-SEM) and diffuse reflectance spectroscopy (DRS) measurements. FE-SEM studies prove that smaller nanoparticles of gold are deposited uniformly on calcite if electroless deposition method was employed and DRS measurements show the characteristic surface plasmon resonance of gold nanoparticles.
\end{abstract}

Keywords. Calcite; gold nanoparticles; electroless deposition; galvanic displacement reaction.

\section{Introduction}

Gold nanoparticles deposited on various substrates have been widely used as active catalysts, e.g. for the oxidation of alcohols, epoxidation of alkenes, $\mathrm{CO}$ oxidation, selective $\mathrm{O}_{2}$ reduction, etc. (Schimpf et al 2002; Choudhary et al 2005; Hughes et al 2005). Gold nanoparticles are very stable which makes them poor in catalysis but deposited gold nanoparticles possess better catalytic activity. The deposited gold nanoparticles are also efficient catalysts in pollution control, chemical sensing and fuel cells (Moshfegh 2009). Gold nanoparticles deposited on substrates possess wide range of applications in the field of biological sensing and surface enhanced Raman scattering (Evans et al 2007; Batista et al 2009). Au nanoparticles deposited substrates have also been used for studying substrate based fluorescence enhancement (Goldys and Xie 2008). Gold nanoparticles have been deposited on different substrates by various physical and chemical methods. A brief review on the reported methods for the deposition of gold nanoparticles on different substrates is given below.

Gold nanoparticles have been deposited on roughened surfaces of $\mathrm{CaF}_{2}$ by glancing angle deposition (Evans et al 2007). Polycarbonate membranes (PCM) of various pore sizes have been used as templates for the deposition of $\mathrm{Au}$ nanoparticles (Batista et al 2009). The deposition of gold

\footnotetext{
*Author for correspondence (jeevafcy@iitr.ernet.in)
}

nanoparticles on carbon nanotubes has been done by a direct deposition method (Zhang et al 2009). Microwave assisted and thermal decomposition methods have been reported for the deposition of gold nanoparticles on different substrates (Xue et al 2001; Raghuveer et al 2006). Homogeneous deposition-precipitation has been used to deposit gold nanoparticles on $\mathrm{MgO}, \mathrm{CaO}, \mathrm{BaO}, \mathrm{SrO}_{2}, \mathrm{Al}_{2} \mathrm{O}_{3}, \mathrm{Ga}_{2} \mathrm{O}_{3}, \mathrm{In}_{2} \mathrm{O}_{3}$ and other transition and rare earth metal oxides (Choudhary and Dumbre 2009; Choudhary et al 2009). Gold nanoparticles have been deposited on highly oriented pyrolytic graphite (Limat et al 2009) and $\mathrm{Cu}_{2} \mathrm{O}$ and $\mathrm{ZnO}$ single crystal planes by electrochemical deposition (Read et al 2009). Gold nanolayers have been deposited on polymers such as polytetrafluoroethylene (PTFE) and polyethyleneterephthalate (PET) films by sputtering (Slepicka et al 2009). Deposition of gold nanoparticles on monolayer graphene epitaxied SiC (0001) substrate has been reported (Premlal et al 2009). $\mathrm{Au}$ nanoclusters have been deposited on $\mathrm{CeO}_{2}$ nanorods and $\mathrm{CeO}_{2}$ nanoparticles by deposition precipitation (Huang et al 2009).

Mercaptopropyltrimethoxysilane (MCPTMS) functionalized indium tin oxide electrode has been coated with gold nanoparticles by an electrochemical method (Dai and Compton 2006). Au nanoparticles have been deposited on the surface of sodium trititanate nanotubes by an ion-exchange method (Tsai et al 2009). Gold nanoparticles have been deposited on $p$-type Si (100) surface by an electrochemical method (Fang et al 2007). Gold nanoparticles have been deposited on sapphire substrate (0001 plane) by pulsed laser deposition (PLD) (Kukreja et al 2008). Photo-induced chemical method has been employed for the deposition of gold nanoparticles on GaAs and InP (Dmitruk et al 2008). 
Au nanoparticles have also been deposited on submicronsized polystyrene spheres by surface modification followed by electroless plating (Kobayashi et al 2007).

The reported methods consist of complicated and expensive procedures for the deposition of gold nanoparticles on the substrates. In the present study, a simple method for the deposition of gold nanoparticles on a cheaper substrate such as calcite has been reported. A comparison of electroless deposition and galvanic displacement methods has also been carried out. Apart from gold chloride, remaining chemicals used throughout the procedure are economical and non-hazardous.

\section{Experimental}

All the chemicals used throughout the experiments were of analytical grade. Millipore ${ }^{\circledR}$ water was used for making aqueous solutions. Synthesis of calcite and its surface modification with ammonium oxalate was based on reported literature (Srikanth and Jeevanandam 2009). Gold nanoparticles were deposited on calcite by two different methods: electroless deposition and galvanic displacement reaction. The electroless deposition was carried out on the surface modified calcite using silver nitrate and formaldehyde (Chou and Ren 2000). In the galvanic displacement reaction, silver nanoparticles deposited calcite, prepared by a previously reported method (Srikanth and Jeevanandam 2009), was used and the silver nanoparticles were galvanically displaced with gold nanoparticles (Liu and Yang 2006). More details on the deposition experiments are as follows.

For the electroless deposition (scheme 1), calcite was synthesized by homogeneous precipitation using urea and cal- cium nitrate and calcite was subsequently surface modified with ammonium oxalate. Then, about $10 \mathrm{~mL}$ of $5 \mathrm{mM}$ aqueous gold chloride solution was mixed with $100 \mathrm{mg}$ of the surface modified calcite and stirred for $2 \mathrm{~h}$ at room temperature. The sample was washed with water and ethanol followed by drying inside a drying cabinet. The colour of the sample turned from white to light yellow indicating that gold ions are attached to the surface modified calcite. The gold ions were then reduced using $10 \mathrm{mM}$ aqueous sodium borohydride solution $(10 \mathrm{ml})$ in the presence of tri-sodium citrate $(0 \cdot 1 \mathrm{~g})$ (Jana et al 2001). During the reduction, yellow coloured sample turned into pink. The electroless deposition experiments were carried out for different time intervals (30, $90,180 \mathrm{~min}$ ) at room temperature.

For the galvanic displacement reaction, initially, the $\mathrm{Ag}$ nanoparticles deposited calcite was prepared. Then, about $100 \mathrm{mg}$ of silver nanoparticles deposited calcite was taken and to it $5 \mathrm{mM}$ aqueous gold chloride solution $(10 \mathrm{ml})$ was added. The contents were kept for equilibrium at room temperature up to $12 \mathrm{~h}$ under stirring. The products collected were washed and dried in an oven and the samples obtained were black in colour. The nomenclature of various samples, prepared in the present study, is given in table 1.

Among various colours which are light of a particular wavelength, a material with black colour absorbs light of different wavelengths especially in the visible region of the spectrum. In the present study, there are two phases in the coating; one is metallic and another one is non-metallic oxide phase. The high reflectivity of the metals is due to high skin effect where electromagnetic radiation cannot penetrate far into the metal because of the high electron density. In the present system, yellow colour is due to the presence of gold ion. Both pink and black coloured calcite samples contain

Step 1: $\mathrm{Ca}\left(\mathrm{NO}_{3}\right)_{2}+$ Urea $\stackrel{80^{\circ} \mathrm{C}, 6 \mathrm{~h}}{\longrightarrow}$ Calcite

Step 2: Calcite $(100 \mathrm{mg}) \underset{24 \mathrm{~h}}{\stackrel{\text { Ammonium oxalate }}{\longrightarrow}}$ Surface modified calcite

Step 3: Surface modified calcite $\stackrel{\mathrm{HAuCl}_{4}}{\longrightarrow}$ Surface modified Calcite-Au ${ }^{3+}$

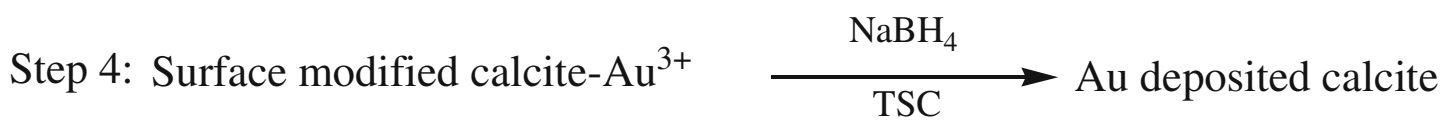

Scheme 1. Steps involved in electroless method for deposition of gold nanoparticles on calcite. 
gold, $\mathrm{C}$ and $\mathrm{O}$. Here, gold is the metallic phase; calcite and oxalate are the non-metallic phases. Further, particle or crystallite size also affects the reflectivity of electromagnetic radiation. The contradictory observation, in the present study, is that the bigger particle sized gold produced by the displacement reaction shows black colour. This means that there may not be continuous gold distribution. If this is so, the light can penetrate far into the calcite leading to more absorbance.

\subsection{Characterization}

Powder XRD patterns were obtained using a Brucker AXS D8 powder diffractometer operating with $\mathrm{CuK}_{\alpha}$ radiation (40 kV, $45 \mathrm{~mA}, \lambda=1.5406 \AA$ ) with a $0.02^{\circ}$ step scan per min. The diffraction patterns obtained were compared with the reference JCPDS files. SEM images were obtained using a FEI Quanta 200F microscope operating at an accelerating

Table 1. Nomenclature of the gold deposited calcite samples prepared.

\begin{tabular}{lll}
\hline Sample & Preparation method & Experimental details \\
\hline Sample 1 & Electroless deposition & Reduction time, $30 \mathrm{~min}$ \\
Sample 2 & Electroless deposition & Reduction time, $90 \mathrm{~min}$ \\
Sample 3 & Electroless deposition & Reduction time, $180 \mathrm{~min}$ \\
Sample 4 & Galvanic displacement reaction & Equilibrium time, $1 \mathrm{~h}$ \\
Sample 5 & Galvanic displacement reaction & Equilibrium time, $12 \mathrm{~h}$ \\
\hline
\end{tabular}
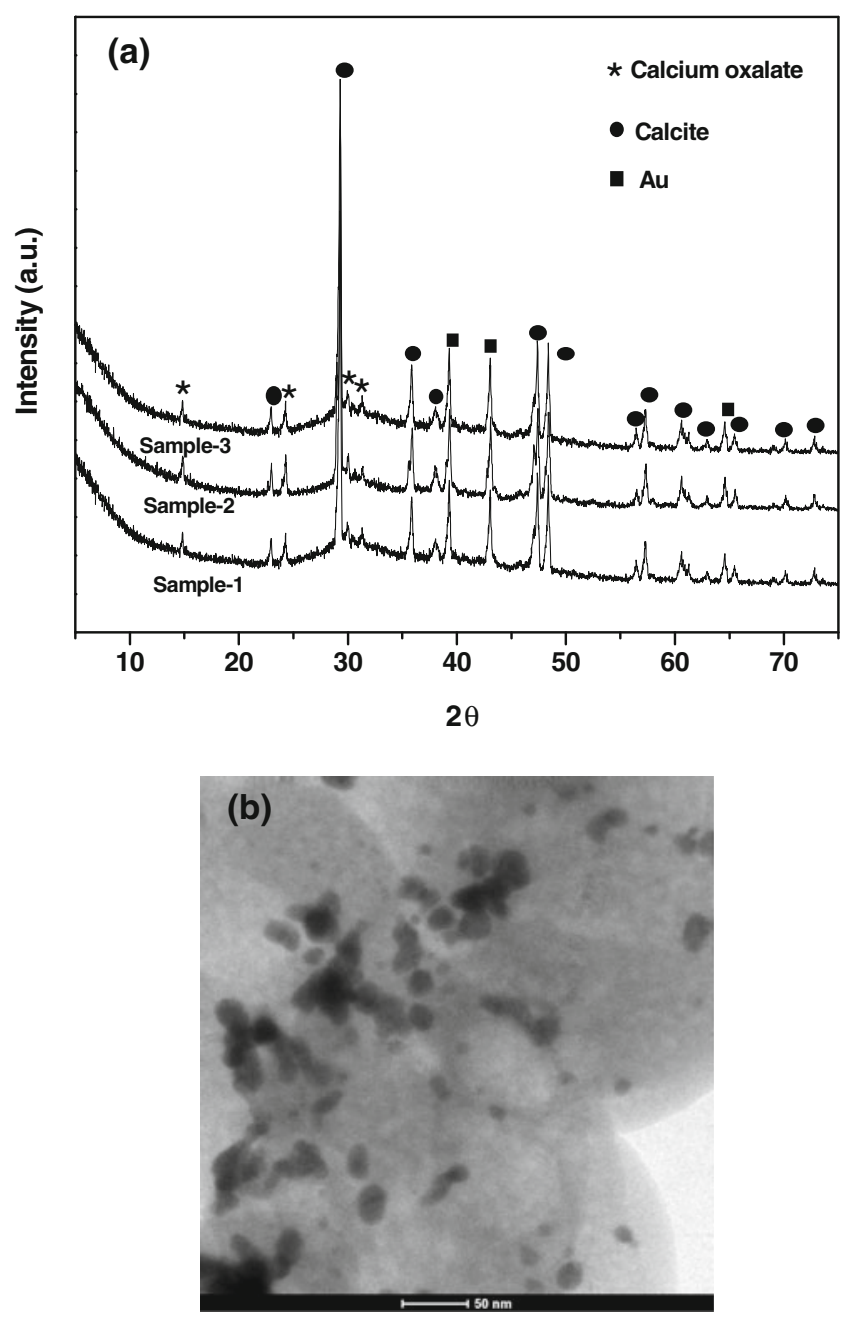

Figure 1. (a) XRD patterns and (b) TEM image of gold deposited calcite samples prepared by electroless deposition.
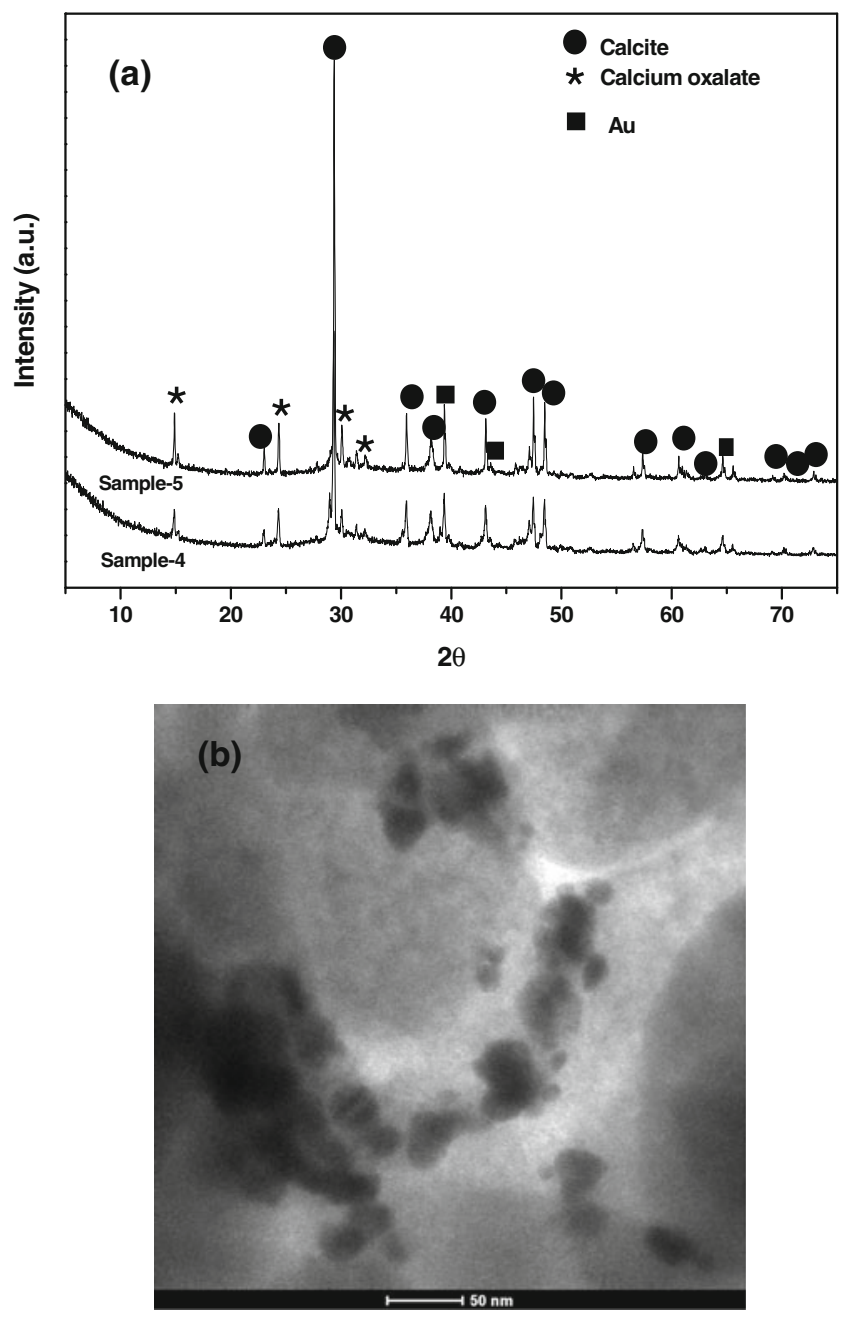

Figure 2. (a) XRD patterns and (b) TEM image of gold deposited calcite samples prepared by galvanic displacement. 
voltage of $20 \mathrm{kV}$. TEM images were recorded using a TECNAI G ${ }^{2}$ instrument operating at $200 \mathrm{kV}$. The powder samples were dispersed in ethanol, sonicated for a few min and then one drop each was allowed to dry in air on carbon coated copper grids. To study the surface plasmon resonance of $\mathrm{Au}$ nanoparticles deposited on calcite, a Shimadzu ${ }^{\circledR}$ UV-3600
UV-Vis-NIR spectrophotometer was used along with an integrated sphere (ISR-3100). About $50 \mathrm{mg}$ of the gold deposited calcite samples were mixed with about $3 \mathrm{~g}$ of $\mathrm{BaSO}_{4}$ (reference). The powders were packed in the sample holder and the reflectance spectra were recorded in the $200-800 \mathrm{~nm}$ wavelength range.

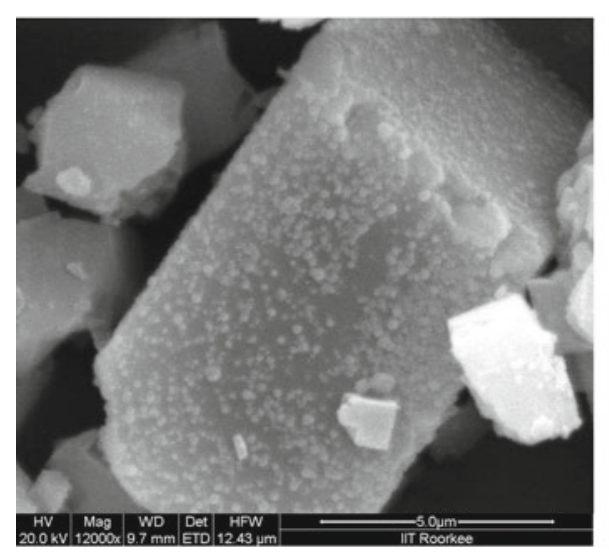

Sample-1

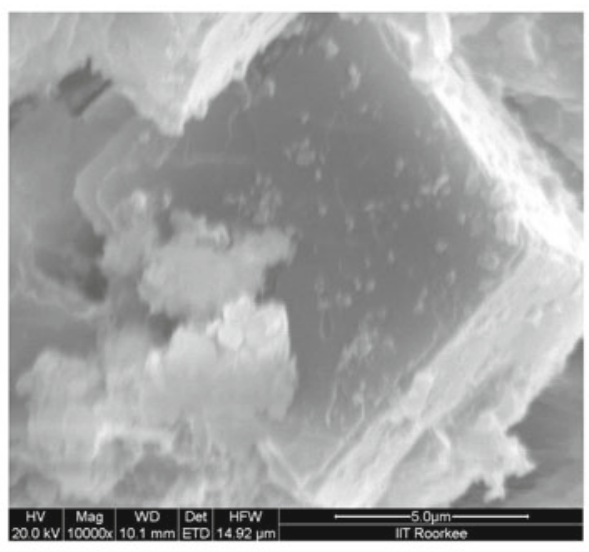

Sample-3

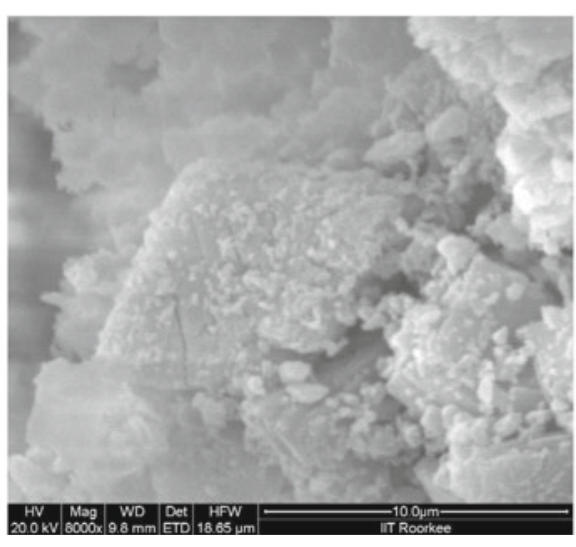

Sample-5

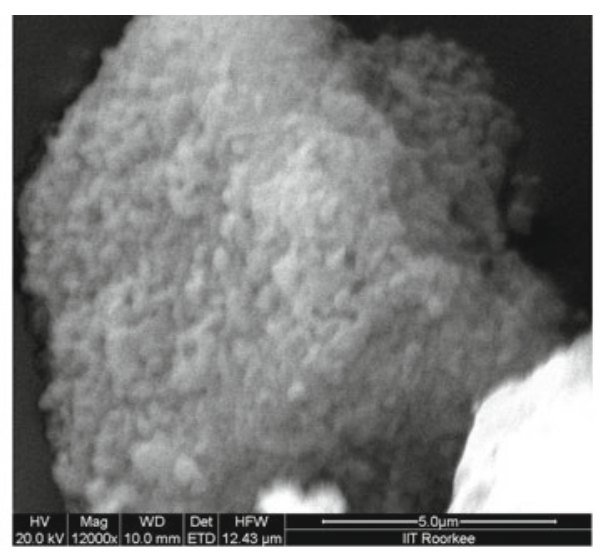

Sample-2

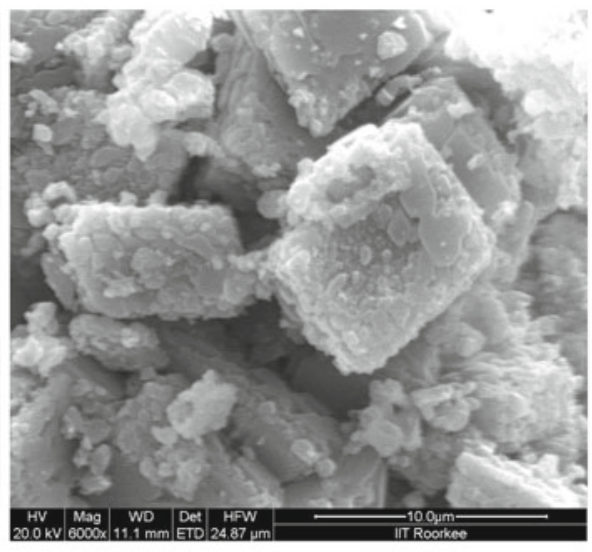

Sample-4

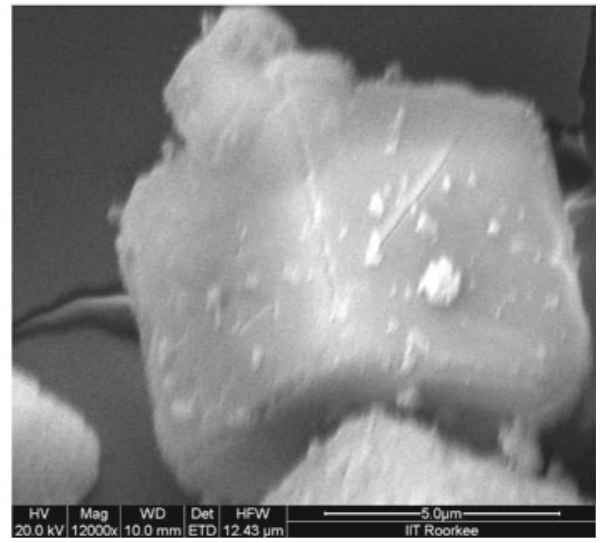

Sample-6

Figure 3. FE-SEM images of gold deposited calcite samples. 
Table 2. Mean particle size of gold in Au-deposited calcite samples.

\begin{tabular}{lcc}
\hline Sample & Mean size $(\mathrm{nm})$ & Standard deviation $(\mathrm{nm})$ \\
\hline Sample 1 & 149 & $25 \cdot 0$ \\
Sample 2 & 363 & $23 \cdot 0$ \\
Sample 3 & 283 & $26 \cdot 0$ \\
Sample 4 & 404 & $31 \cdot 0$ \\
Sample 5 & 329 & $18 \cdot 9$ \\
\hline
\end{tabular}

\section{Results and discussion}

\subsection{X-ray diffraction and TEM analysis}

The powder diffraction patterns for the deposition of gold nanoparticles on calcite substrate by electroless deposition are shown in figure 1. The diffraction patterns show peaks due to calcite (JCPDS File No. 85-0849), calcium oxalate monohydrate (JCPDS File No. 77-1160), and gold (04-0784); during the surface modification with ammonium oxalate, part of the calcite is converted into calcium oxalate (Srikanth and Jeevanandam 2009). The crystallite size of gold, calculated for the three samples prepared
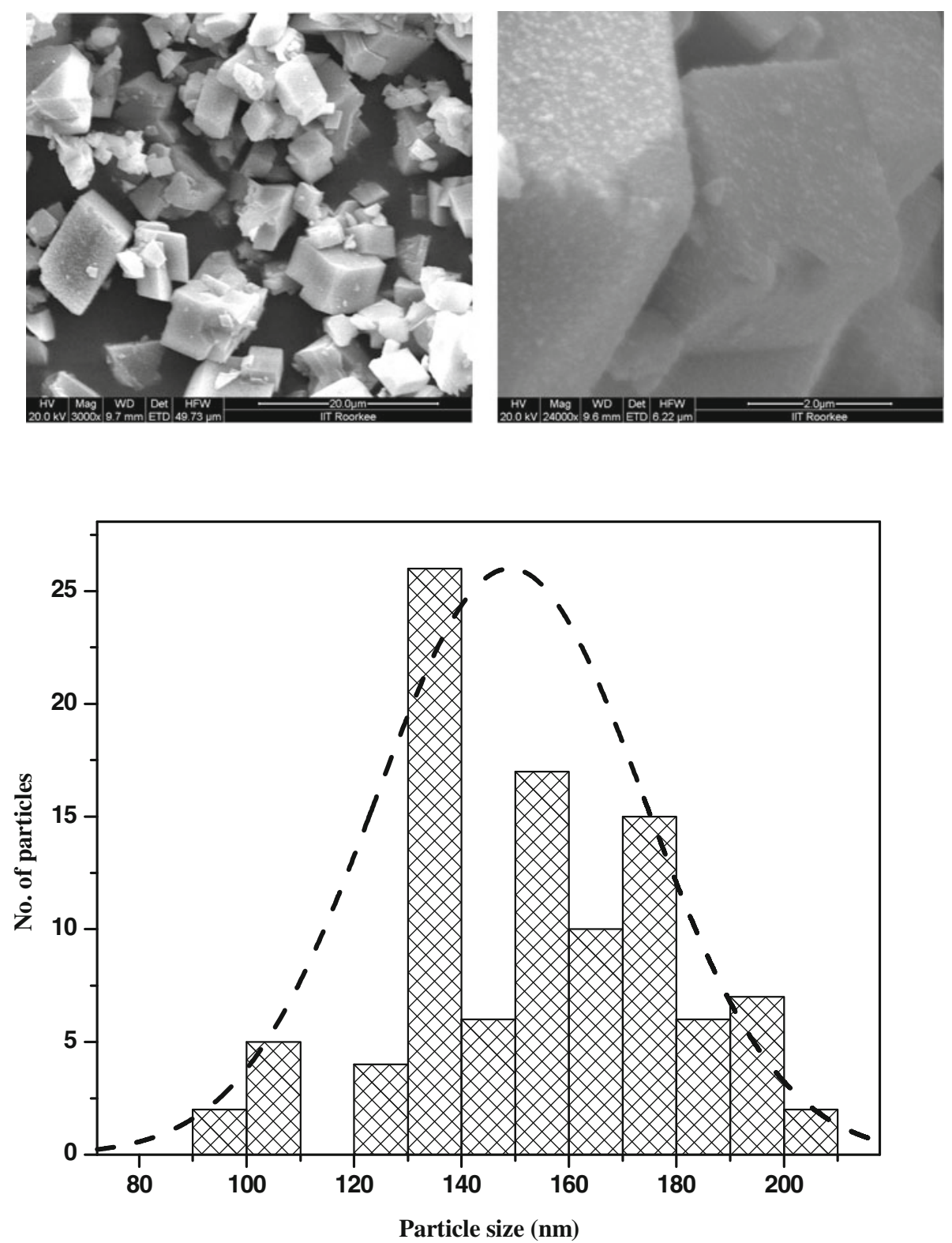

Figure 4. FE-SEM images of gold nanoparticles deposited calcite, prepared by electroless deposition (sample 1), under two different magnifications. The particle size histogram is also shown. 
by electroless deposition using Debye-Scherrer's formula, was found to be about $38 \mathrm{~nm}$. This is in good agreement with the particle size $(\sim 37 \mathrm{~nm})$ obtained by TEM measurements (figure 1b, sample 1). Figure 2 represents XRD patterns for the gold deposited calcite, prepared by galvanic displacement reaction (samples 4 and 5). The characteristic peaks of gold (111), (200) and (220) are again found in addition to those due to calcite and calcium oxalate monohydrate. The crystallite size of the gold nanoparticles from XRD measurements was found to be around $70 \mathrm{~nm}$. TEM image (figure $2 \mathrm{~b}$, sample 5) shows gold nanoparticles with size ranging from about 35 to $70 \mathrm{~nm}$.

\subsection{FE-SEM, EDXA and UV-Vis spectroscopy results}

The morphology of calcite on deposition of gold nanoparticles was studied by FE-SEM analysis (figure 3).

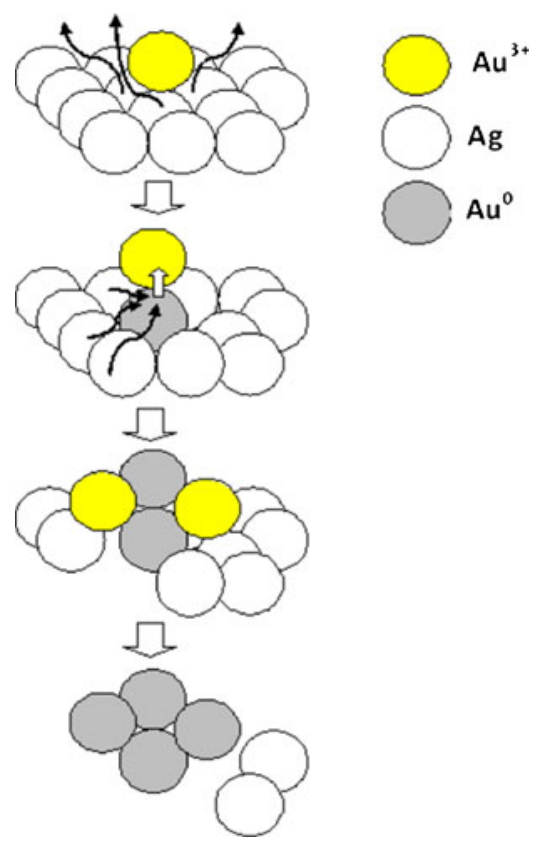

Scheme 2. Pictorial representation of growth of gold particles in displacement reaction. Arrows indicate oxalate groups.
From the FE-SEM images it is clear that gold nanoparticles are deposited on the surface of calcite by both the methods. The mean particle size of gold obtained from the FE-SEM images are given in table 2. For the gold deposited calcite samples prepared by electroless deposition, the mean particle size of $\mathrm{Au}$ varies from about 150 to $360 \mathrm{~nm}$. In the case of samples prepared by galvanic displacement, the mean particle size varies between about 280 and $400 \mathrm{~nm}$. Moreover, electroless deposition leads to the formation of uniform, smaller and well separated gold nanoparticles (e.g. sample 1) compared to the galvanic displacement reaction (e.g. sample 5). FE-SEM images recorded under different magnifications for a sample prepared by electroless deposition (sample 1, figure 4) show that the sample consists of gold nanoparticles with uniform size (mean particle size $=149 \pm 25 \mathrm{~nm}$ ) on the calcite.

The galvanic displacement reaction leads to the formation of bigger $\mathrm{Au}$ nanoparticles (about 280 to $400 \mathrm{~nm}$ ) on calcite, and the standard deviation is similar to the samples which were prepared by electroless deposition method. During the galvanic displacement reaction, when displacement of silver with gold takes place, there is no control on the size of the deposited Au nanoparticles, which results in a bigger particle size. From FE-SEM results (figure 3 and table 2), it is also clear that, among the 30, 60 and $90 \mathrm{~min}$ electroless deposition time intervals, $30 \mathrm{~min}$ is the best for the uniform deposition of gold nanoparticles; longer deposition time leads to an increase in the Au particle size. Also, the surface modification of calcite with ammonium oxalate is important for the successful electroless deposition of $\mathrm{Au}$ nanoparticles. If surface unmodified calcite is employed, it leads to poor deposition of $\mathrm{Au}$ nanoparticles (figure 3, sample 6).

In the ammonium oxalate treatment of calcite, one end of oxalate is attached with calcite while the other end is free for the formation of either $\mathrm{Ag}^{+}$or $\mathrm{Au}^{3+}$ compound of oxalate. The $\mathrm{Ag}^{+}$ions per unit area are more than the number of $\mathrm{Au}^{3+}$ since $\mathrm{Au}^{3+}$ requires three oxalate end groups for its settlement. In other words, the availability of gold atoms must be lower than the availability of silver atoms per unit area
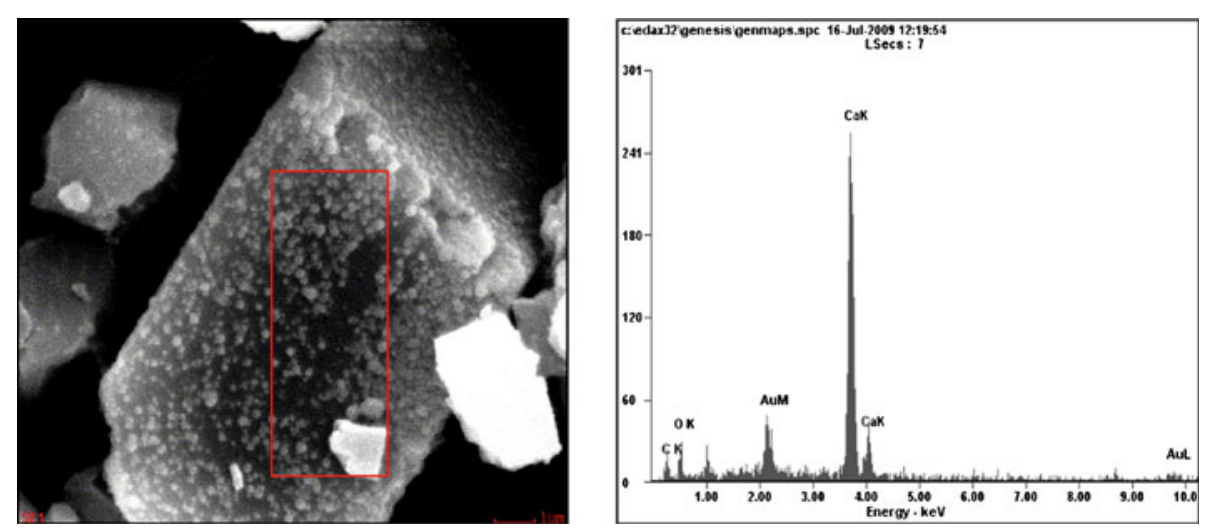

Figure 5. Typical EDXA data of gold deposited calcite (sample 1). 
of calcite. Further, the reaction centres in gold containing calcite are less than that on the silver containing calcite. Upon reaction with sodium borohydride, in the presence of sodium citrate, the reduction of each $\mathrm{Au}^{3+}$ takes place with the borohydride oxidation. Hence there is no chance for the growth of gold on gold. Whereas, in the displacement reaction, the $\mathrm{Au}^{3+}$ ions are first adsorbed over a silver atom and three such adjacent silver atoms are involved in the reduction of an $\mathrm{Au}^{3+}$ ion into gold. Here, there is a chance for the adsorption of $\mathrm{Au}^{3+}$ ion on already deposited gold atoms which are in contact with silver atoms. The electron transfer may take place from silver atom to $\mathrm{Au}^{3+}$ through gold atom. This kind of reduction of $\mathrm{Au}^{3+}$ on gold leads to the growth and finally bigger particle size of gold. A pictorial representation of the growth of gold particles in the displacement reaction is shown in scheme 2 .

The presence of gold on the surface of calcite was supported by EDXA results too (figure 5). The image mapping for different elements supported the presence of $\mathrm{Ca}, \mathrm{C}, \mathrm{O}$ and $\mathrm{Au}$ in the samples. The solution $\mathrm{pH}$ determines the reaction type which may lead to the deposition of boron along with the metal (Mallory and Hajdu 1990). The $\mathrm{pH}$ during electroless deposition of gold was 7.2. In the present study, from EDX analysis, boron could not be detected. This indicates the absence of boron in the products within the detection limit of the EDX analysis. The atomic percent of gold deposited in all the samples prepared by two methods is nearly the same, about 3 atom \% (see table 3). However, advantage of the electroless deposition is the formation of smaller, uniform Au nanoparticles on calcite. Yet another important characterization technique for the gold deposited calcite samples is diffuse reflectance spectroscopy (DRS). The surface plasmon resonance band, observed at about 520 to $550 \mathrm{~nm}$ in all the gold deposited calcite samples prepared by the two methods (figure 6), indicates the presence of gold nanoparticles on calcite.

\subsection{Proposed mechanism for deposition of gold nanoparticles}

The proposed mechanism for the deposition of Au nanoparticles on calcite by electroless deposition and galvanic displacement methods is shown in scheme 3 . In the case of electroless deposition, the surface modification of calcite with ammonium oxalate makes the surface of calcite attached

Table 3. Atomic percent of elements present in gold deposited calcite samples.

\begin{tabular}{lllll}
\hline Sample & $\% \mathrm{Ca}$ & $\% \mathrm{C}$ & $\% \mathrm{O}$ & $\% \mathrm{Au}$ \\
\hline Sample 1 & $27 \cdot 1$ & $22 \cdot 8$ & $43 \cdot 3$ & $02 \cdot 8$ \\
Sample 2 & $21 \cdot 3$ & $31 \cdot 7$ & $45 \cdot 6$ & $03 \cdot 4$ \\
Sample 3 & $18 \cdot 9$ & $30 \cdot 6$ & $48 \cdot 4$ & $03 \cdot 8$ \\
Sample 4 & $23 \cdot 1$ & 27.4 & $46 \cdot 0$ & $03 \cdot 6$ \\
Sample 5 & 27.2 & $28 \cdot 2$ & $40 \cdot 4$ & $04 \cdot 3$ \\
\hline
\end{tabular}
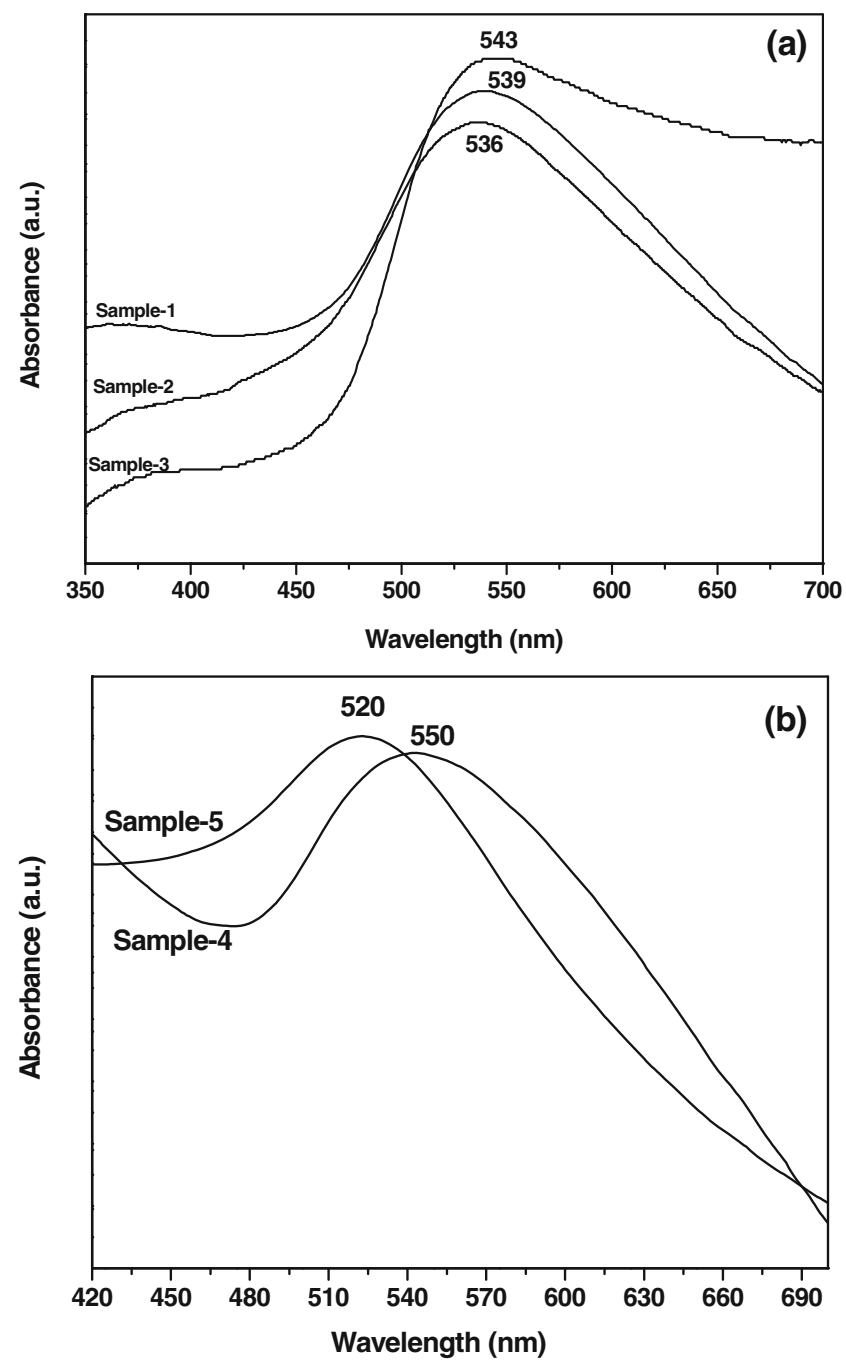

Figure 6. UV-Vis spectra of gold deposited calcite samples prepared by (a) electroless deposition and (b) galvanic displacement reaction.

with negative oxalate groups and the $\mathrm{Au}^{3+}$ ions attach to these negative oxalate groups. The reduction with sodium borohydride, in the presence of tri-sodium citrate which acts as a capping agent, leads to the deposition of Au nanoparticles on calcite. An electroless deposition experiment performed using surface unmodified calcite led to a poor deposition of Au nanoparticles on calcite (see figure 3, sample 6). This proves that surface modification is necessary for uniform deposition of gold nanoparticles. In the galvanic displacement reaction, the replacement of $\mathrm{Ag}$ by $\mathrm{Au}$ is based on their reduction potentials. The standard reduction potential for $\mathrm{Ag}^{+} / \mathrm{Ag}$ system is $+0.767 \mathrm{~V}$, while that for $\mathrm{Au}^{3+} / \mathrm{Au}$ is $+0.995 \mathrm{~V}$. Due to the higher reduction potential of $\mathrm{Au}^{3+} / \mathrm{Au}$ system, the $\mathrm{Au}^{3+}$ ions are reduced to $\mathrm{Au}$ on calcite with the concomitant oxidation of $\mathrm{Ag}$ to $\mathrm{Ag}^{+}$.

$$
\mathrm{AuCl}_{4}^{-}+3 \mathrm{Ag} \rightarrow \mathrm{Au}+3 \mathrm{AgCl}+\mathrm{Cl}^{-} .
$$




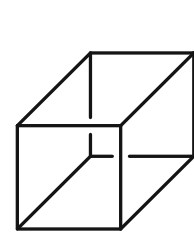

Calcite

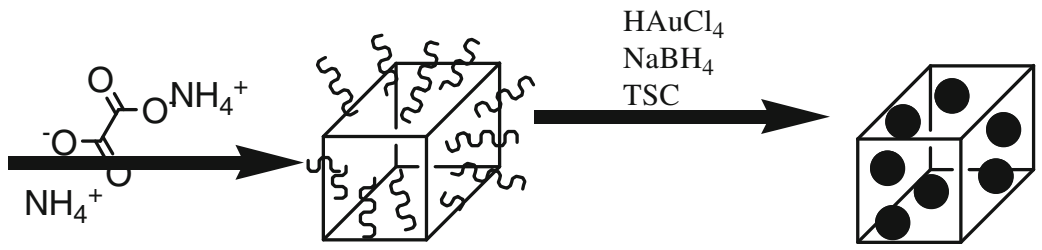

Surface modified calcite

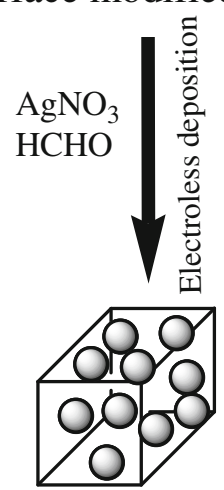

Gold nanoparticles deposited calcite

\section{Silver nanoparticles deposited calcite}

Scheme 3. Proposed mechanism for deposition of Au nanoparticles on calcite.

\section{Conclusions}

Gold nanoparticles have been deposited on synthetic calcite using two different methods: electroless deposition and galvanic displacement reaction. Electroless deposition is better for a uniform deposition of smaller Au nanoparticles on calcite compared to the galvanic displacement reaction. The present method is simple, economical and may be extended to other substrates with possible applications in catalysis, optoelectronics, sensors, etc.

\section{Acknowledgements}

The generous funding from the Department of Science and Technology, Government of India (Project No. SR/S1/PC$06 / 2007$ ) is acknowledged with gratitude. Thanks are also due to the Institute Instrumentation Centre, IIT Roorkee, for providing XRD, TEM and FE-SEM facilities. We want to thank the anonymous reviewer for his valuable comments.

\section{References}

Batista E A, dos Santos D P, Andrade G F S, Sant'Ana A C, Brolo A G and Temperini M L A 2009 J. Nanosci. Nanotechnol. 93233

Chou K S and Ren C Y 2000 Mater. Chem. Phys. 64241

Choudhary V R and Dumbre D K 2009 Catal. Commun. 101738

Choudhary V R, Dhar A, Jana P, Jha R and Uphade B S 2005 Green Chemistry 7768

Choudhary V R, Dumbre D K and Bhargava S K 2009 Ind. Eng. Chem. Res. 489471

Dai X and Compton R G 2006 Anal. Sci. 22567

Dmitruk N, Barlas T, Dmytruk A, Korovin A and Romanyuk V 2008 J. Nanosci. Nanotechnol. 8564
Evans P G, Passian A and Ferrell T L 2007 Ultramicroscopy 107 1012

Fang J, You H, Ding B and Song X 2007 Electrochem. Commun. 9 2423

Goldys E M and Xie F 2008 Sensors 8886

Huang X S, Sun H, Wang L C, Liu Y M, Fan K N and Cao Y 2009 Appl. Catal. $\mathbf{B 9 0} 224$

Hughes M D et al 2005 Nature 4371132

Jana N R, Gearheart L and Murphy C J 2001 Chem. Commun. 7617

Kobayashi Y, Tadaki Y, Nagao D and Konno M 2007 J. Phys.: Conf. Ser. 61582

Kukreja L M, Koslowski B, Steiner R, Plettl A and Ziemann P 2008 Appl. Surf. Sci. 2547336

Limat M, Foti G, Hugentobler M, Stephan R and Harbich W 2009 Catal. Today 146378

Liu Y C and Yang S J 2006 Electrochim. Acta 521925

Mallory G O and Hajdu J B 1990 Electroless plating: Fundamentals and applications (American Electroplaters and Surface Finishers Society)

Moshfegh A Z 2009 J. Phys. D: Appl. Phys. 42 233001/1

Premlal B, Cranney M, Vonau F, Aubel D, Casterman D, De souza M M and Simon L 2009 Appl. Phys. Lett. 94263115

Raghuveer M S, Agrawal S, Bishop N and Ramanath G 2006 Chem. Mater. 181390

Read C G, Steinmiller E M P and Choi K S 2009 J. Am. Chem. Soc. 13112040

Srikanth C K and Jeevanandam P 2009 Appl. Surf. Sci. 2557153

Schimpf S, Lucas M, Mohr C, Rodemerck U, Bruckner A, Radnik J, Hofmeister H and Claus P 2002 Catal. Today 7263

Slepicka P, Kolska Z, Nahlik J, Hnatowicz V and Svorcik V 2009 Surf. Interf. Anal. 41741

Tsai J Y, Chao J H and Lin C H 2009 J. Mol. Catal. A298 115

Xue B, Chen P, Hong Q, Lin J and Tan K L 2001 J. Mater. Chem. 112378

Zhang R, Hummelgard M and Olin H 2009 Mater. Sci. Eng. B158 48 